\title{
Original Article \\ Genotyping ITS and matK regions of Hedera nepalensis K. Koch in Vietnam
}

\author{
Pham Thi Hong Nhung, Do Hanh Nguyen, Bui Thi Yen, \\ Do Thi Le Hang, Vu Thi Thom, Dinh Doan Long*
}

VNU School of Medicine and Pharmacy, 144 Xuan Thuy, Cau Giay, Hanoi, Vietnam

Received 12 May 2020

Revised 21 May 2020; Accepted 23 May 2020

\begin{abstract}
This study develops procedures for cloning ITS and matK genes on six specimens in order to exploit and conserve the genetic resources of $H$. nepalensis and evaluate its genetic diversity based on molecular markers. The study methods include DNA extraction from dried leaf samples, amplification of ITS and matK regions using PCR, sequencing and comparing with the sequences on Genbank. The study results include a successfully-established process of cloning ITS and matK genes; successful amplification and sequencing of the ITS and matK regions. The results also show that four samples (N1-N4) were 100\% homologous to H. nepalensis and H1and H2 samples were $100 \%$ homologous to $H$. helix. The results provide data and tools for further studies of exploitation and development of the $H$. nepalensis K. Koch genetic resources in Vietnam.
\end{abstract}

Keywords: ITS, matK, Hedera nepalensis K. Koch, PCR.

\footnotetext{
${ }^{*}$ Corresponding author.

E-mail address: dinhdoanlong.smp@ gmail.com
}

https://doi.org/10.25073/2588-1132/vnumps.4241 


\title{
Xây dựng quy trình phân tích gen ITS và matK của Dây thường xuân (Hedera nepalensis K. Koch) ở Việt Nam
}

\author{
Phạm Thị Hồng Nhung, Đỗ Hạnh Nguyên, Bùi Thị Yến, \\ Đỗ Thị Lệ Hằng, Vũ Thị Thơm, Đinh Đoàn Long* \\ Khoa Y Dược, Đại học Quốc gia Hà Nội, 144 Xuân Thủy, Cầu Giấy, Hà Nội, Việt Nam \\ Nhận ngày 12 tháng 5 năm 2020 \\ Chỉnh sửa ngày 21 tháng 5 năm 2020; Chấp nhận đăng ngày 23 tháng 5 năm 2020
}

\begin{abstract}
Tóm tắt: Dây thường xuân (Hedera nepalensis $\mathrm{K}$. Koch) là cây thuốc thuộc chi Hedera, họ Nhân sâm (Araliaceae) phân bố hẹp trên thế giới, trong đó có một số tỉnh vùng núi phía Bắc Việt Nam. Loài này được chứng minh có nhiều tác dụng dược lý như chống oxy hóa, bảo vệ thần kinh, chống viêm, giảm đau, ... và đặc biệt có tiềm năng trong điều trị ung thư và đái tháo đường. Để định hướng khai thác và bảo tồn bền vững nguồn gen Dây thường xuân một cách hiệu quả, đánh giá đa dạng di truyền dựa trên chỉ thị phân tử làthực sự cần thiết. Vì vậy, chúng tôi tiến hành xây dựng quy trình nhân dòng đoạn gen ITS và $m a t K$ trền 06 mẫu Hedera. Phương pháp nghiên cứu bao gồm: tách chiết $\mathrm{ADN}$ tổng số tách từ mẫu lá khô, nhân dòng đoạn gen $I T S$ và $m a t K$ bằng phản ứng $\mathrm{PCR}$ dùng mồi đặc hiệu, giải trình tự và so sánh độ tương đồng với các mẫu trên Genbank. Kết quả cho thấy chúng tồi đã xây dựng thành công quy trình nhân dòng gen $I T S$ và $m a t K$. Các mẫu nghiên cứu đều được khuếch đại và giải trình tự thành công $100 \%$ trong đó có 04 mẫu (N1-N4) có trình tự tương đồng cao với $H$. nepalensis và 02 mẫu $(\mathrm{H} 1$ và $\mathrm{H} 2)$ có trình tự tương đồng cao với $H$. helix. Các kết quả này sẽ cung cấp công cụ và số liệu cho các nghiên cứu tiếp theo nhằm đánh giá đa dạng di truyền nguồn gen Dây thường xuân ở Việt Nam.
\end{abstract}

Tù khóa: ITS, matK, Dây thường xuân (Hedera nepalensis K. Koch), PCR.

\section{Mở đầu}

Dây thường xuân (tên khoa học Hedera nepalensis $\mathrm{K}$. Kock) là một loài thuộc chi Hedera, họ Nhân sâm (Araliaceae) [1]. Trên thế giới, loài này phân bố hẹp ở các nước châu Âu, dãy Himalaya và một số nước châu Á trong đó có một số tỉnh miền núi phía Bắc tại Việt Nam [2]. Các nghiên cứu gần đây phát hiện trong Dây thường xuân chứa nhiều nhóm chất như: saponin, alkaloid, tanin, terpenoid, các hợp chất phenolic [3]. Trong đó, hai hợp chất hederagenin 3-O- $\alpha$-L-arabinopyranoside và

\footnotetext{
*Tác giả liên hệ.

Địa chỉ email: dinhdoanlong.smp@gmail.com
}

https://doi.org/10.25073/2588-1132/vnumps.4241 pulsatilla saponin A ức chế tế bào ung thư [4], lupeol ức chế dipeptidyl peptidase-4 cho tiềm năng chữa bệnh đái tháo đường [5-7], các hợp chất phenolic có khả năng chống oxy hóa, bảo vệ tế bào thần kinh [5]. Ngoài ra, Dây thường xuân cũng được chứng minh có nhiều tác dụng khác như giảm đau, kháng viêm, chống trầm cảm và chống đông máu [8]. Mặc dù có nhiều tiềm năng như vậy, song hiện nay các nghiên cứu về Dây thường xuân ở Việt Nam còn rất hạn chế, đặc biệt là nghiên cứu về đa dạng di truyền. 
Gen ITS (Internal Transcribed Spacer) và matK (maturase $K$ ) là hai đoạn gen đại diện cho chỉ thị gen nhân và chỉ thị gen lục lạp, có hiệu quả rất cao trong phân tích đa dạng di truyền. Chúng là những chỉ thị gen hữu ích giúp phân loài $[9,10]$. Hai chỉ thị này đã được ứng dụng thành công trong nhiều nghiên cứu đa dạng di truyền và định danh nhiều loài thực vật, có thể kể đến như chi Alium [11] hay chi Dalbergia [12], đặc biệt là chi Hedera [13] hay họ Araliaceae $[14], \ldots$ Chính vì vậy, chúng tôi thực hiện nghiên cứu này nhằm xây dựng được quy trình phân tích gen ITS và mat $K$, hướng đến phân tích đa dạng di truyền Dây thường xuân ở Việt Nam.

\section{Vật liệu và phương pháp nghiên cứu}

Vật liệu: mẫu được thu thập và định danh bởi Khoa Tài nguyên Dược liệu, Viện Dược liệu, Bộ Y tế. Dựa vào hình thái, có 04 mẫu thuộc loài $H$. nepalensis (N1-N4) và 02 mẫu thuộc loài $H$. helix (H1-H2). Các mẫu lá khô được nghiền mịn trong nitơ lỏng, sau đó bảo quản ở $-30^{\circ} \mathrm{C}$ đến khi tách $\mathrm{ADN}$ tổng số. Tọa độ thu mẫu được trình bày chi tiết trong Bảng 1 .

Bảng 1. Danh sách mẫu thực vật sử dụng trong nghiên cứu

\begin{tabular}{|c|c|c|}
\hline Kí hiệu & $\begin{array}{l}\text { Địa điểm lấy } \\
\text { mẫu }\end{array}$ & Toạ độ địa lý \\
\hline H1 & $\begin{array}{l}\text { Vườn thực vật } \\
\text { Hoa Nam, Trung } \\
\text { Quốc }\end{array}$ & $\begin{array}{l}23^{\circ} 11^{\prime} 12^{\prime \prime} \mathrm{N} \\
113^{\circ} 21^{\prime} 51^{\prime \prime} \mathrm{E}\end{array}$ \\
\hline $\mathrm{H} 2$ & Sa Pa, Lào Cai & $\begin{array}{l}22^{\circ} 21^{\prime} 10.29^{\prime \prime} \mathrm{N} \\
103^{\circ} 51^{\prime} 36.04^{\prime \prime} \mathrm{E}\end{array}$ \\
\hline N1 & \multirow{3}{*}{$\begin{array}{l}\text { Hoàng Su Phì, } \\
\text { Hà Giang }\end{array}$} & $\begin{array}{l}22^{\circ} 39^{\prime} 28.47^{\prime \prime N} \\
104^{\circ} 35^{\prime} 57.14^{\prime \prime} \mathrm{E}\end{array}$ \\
\hline $\mathrm{N} 2, \mathrm{~N} 3$ & & $\begin{array}{l}22^{\circ} 39^{\prime} 18.38^{\prime \prime} \mathrm{N} \\
104^{\circ} 35^{\prime} 45.13^{\prime \prime} \mathrm{E}\end{array}$ \\
\hline N4 & & $\begin{array}{l}22^{\circ} 40^{\prime} 11.06 " \mathrm{~N} \\
104^{\circ} 36^{\prime} 11.85^{\prime \prime} \mathrm{E}\end{array}$ \\
\hline
\end{tabular}

Tách chiết ADN tổng số: ADN được phân lập bằng phương pháp sử dụng GeneJET Plant Genomic ADN Purification Mini Kit (Thermo
Scientific, Mỹ) theo hướng dẫn của hãng sản xuất. Sau đó, $\mathrm{ADN}$ tổng số được kiểm tra và đánh giá thông qua điện di trên gel agarose 1,2 $\%$ và đo độ tinh sạch tại bước sóng $260 \mathrm{~nm}$ và $280 \mathrm{~nm}$.

Nhân dòng gen ITS và $m a t K$ bằng PCR: để có quy trình nhân dòng đặc hiệu và ổn định, chúng tôi tiến hành các thí nghiệm tối ưu nhiệt độ gắn mồi, nồng độ mồi và nồng độ $\mathrm{ADN}$. Trình tự mồi nhân dòng gen ITS là $17 \mathrm{SE}$ (ACGAATTCATGGTCCGGT GAA GTG TTC) và 28SE (TAG AAT TCC CCG GTT CGC TCG CCG TTAC) [15]. Trình tự mồi nhân dòng gen mat $K$ là 390F (CGA TCT ATT CAT TCA ATA TTT C) và 1326R (TCT AGC ACA CGA AAG TCG AAG T) [16]. Sản phẩm của phản ứng PCR được kiểm tra bằng cách điện di trên gel agarose $1,5 \%$, dùng thang chuẩn $\mathrm{ADN}$ GeneRuler 100bp (Thermo Scientific).

Tinh sạch và giải trình tự: $20 \mu \mathrm{L}$ sản phẩm PCR được giải trình tự tại hãng First Base (Malaysia). Kết quả giải trình tự được đọc bằng phần mềm BioEdit version 7.2.6.1.

Xử lý số liệu và phân tích kết quả: phần mềm Sequencher 5.4.6 được sử dụng để tinh chỉnh chuỗi nucleotide. Các trình tự được so sánh mức độ tương đồng với các trình tự có sã̃n trên Genbank thông qua chương trình BLAST (https://blast.ncbi.nlm.nih.gov/Blast.cgi).

\section{Kết quả nghiên cứu}

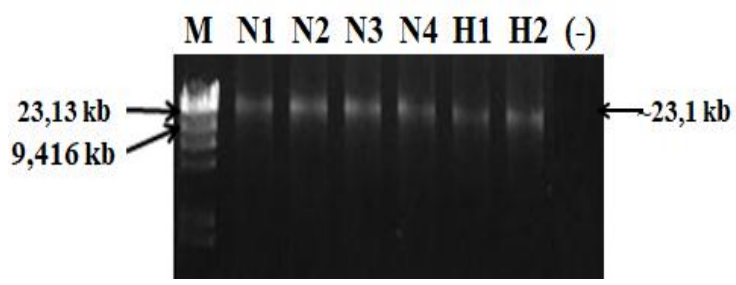

Hình 1. Ảnh điện di $\mathrm{ADN}$ tổng số trên gel agarose 1,2\%. Làn M: Lamda ADN/HindIII marker. Làn N1 $-\mathrm{H} 2$ : Mẫu $\mathrm{ADN}$ nghiên cứu có tên tương ứng. Làn (-): Đối chứng âm.

Tách chiết $\mathrm{ADN}$ tổng số: nồng độ $\mathrm{ADN}$ của 06 mẫu thực vật dao động từ $6,4-19,4 \mathrm{ng} / \mu \mathrm{l}$, có độ tinh sạch với chỉ số $\mathrm{OD}_{260 / 280}$ thu được từ 1,5 
đến 2,70. Kết quả điện di trên gel agarose cho thấy ADN tổng số thu được ít bị đứt gãy, không có băng phụ. Như vậy, ADN tổng số tách chiết từ Dây thường xuân bằng GeneJET Plant Genomic DNA Purification Mini Kit đảm bảo độ tinh sạch và có thể sử dụng cho bước PCR tiếp theo.

Nhân dòng đoạn gen $I T S$ và $m a t K$ :

Tối ưu nhiệt độ gắn mồi: chúng tôi tiến hành PCR với 9 nhiệt độ xung quanh nhiệt độ gắn mồi tham khảo cho 2 gen ITS và matK. Kết quả điện di trên gel agarose $1,5 \%$ thể hiện ở Hình $2 \mathrm{~A} 1$, 2B1 cho thấy xuất hiện băng đặc hiệu, sáng rõ tại $51,1^{\circ} \mathrm{C}$ với cả 2 gen ITS và matK. Do đó, chúng tôi lựa chọn $51,1^{\circ} \mathrm{C}$ là nhiệt độ gắn mồi chung cho phản ứng nhân dòng gen ITS và matK.

Tối ưu nồng độ ADN: chúng tôi chọn dải nồng độ: 0,$75 ; 1,25 ; 2,5 ; 5 ; 10 ; 20 \mathrm{ng} / \mu \mathrm{L}$ đối với gen ITS. Với gen matK, $\mathrm{t}$ tKgen i $\mathrm{c} 20 \mathrm{ng} / \mu \mathrm{L}$ sản phẩm PCR được nhân dòng cho băng khá sáng nên chúng tôi quyết định chọn dải nồng độ ADN cao hơn là: 1,$25 ; 2,5 ; 5 ; 10 ; 20 ; 40 \mathrm{ng} / \mu \mathrm{L}$. Kết quả điện di ở Hình 2A2, 2B2 cho thấy gen
ITScho băng đặc hiệu, sáng rõ nhất ở nồng độ 5 $\mathrm{ng} / \mu \mathrm{L}$, trong khi gen $m a t K$ là ở khoảng nồng độ $2,5-40 \mathrm{ng} / \mu \mathrm{L}$. Chúng tôi chọn $5 \mathrm{ng} / \mu \mathrm{L}$ là nồng độ $\mathrm{ADN}$ tối ưu chung cho nhân dòng 2 gen ITS và $m a t K$.

Tối ưu nồng độ mồi: tiến hành tối ưu nồng độ mồi ở 03 lô mẫu khác nhau với dải nồng độ 0,$1 ; 0,3 ; 0,9 \mu \mathrm{M}$. Tại nồng độ mồi $0,3 \mu \mathrm{M}$, quá trình nhân dòng 2 gen ITS và $m a t K$ là ổn định nhất, $100 \%$ mẫu nhân dòng thành công. Trong khi đó, một số mẫu có nồng độ mồi 0,1 và 0,9 $\mu \mathrm{M}$ không nhân dòng được gen matK (Hình 2A3, 2B3).

Như vậy, mỗi phản ứng PCR bao gồm $25 \mu \mathrm{L}$ gồm các thành phần: $5 \mu \mathrm{L}$ đệm $5 \mathrm{x}, 2,5 \mu \mathrm{L}$ dNTP mix $0,2 \mathrm{mM}$ mỗi loại, $0,25 \mu \mathrm{L}$ Phusion ADN polymerase $0,02 \mathrm{U} / \mu \mathrm{L}, 0,75 \mu \mathrm{L}$ mỗi mồi xuôi $0,3 \mu \mathrm{M}, 14,75 \mu \mathrm{L}$ nước khử ion, $1 \mu \mathrm{L}$ ADN 5 $\mathrm{ng} / \mu \mathrm{L}$. Chu trình nhiệt cho phản ứng $\mathrm{PCR}$ gồm 3 giai đoạn: biến tính ban đầu trong $98^{\circ} \mathrm{C}$ trong 30 giây; 35 chu kỳ: $98^{\circ} \mathrm{C}$ trong 10 giây, gắn mồi ở $55,1{ }^{\circ} \mathrm{C}$ trong 30 giây 30 giây, $72^{\circ} \mathrm{C}$ trong 30 giây; thời gian kéo dài cuối $72^{\circ} \mathrm{C}$ trong 10 phút.

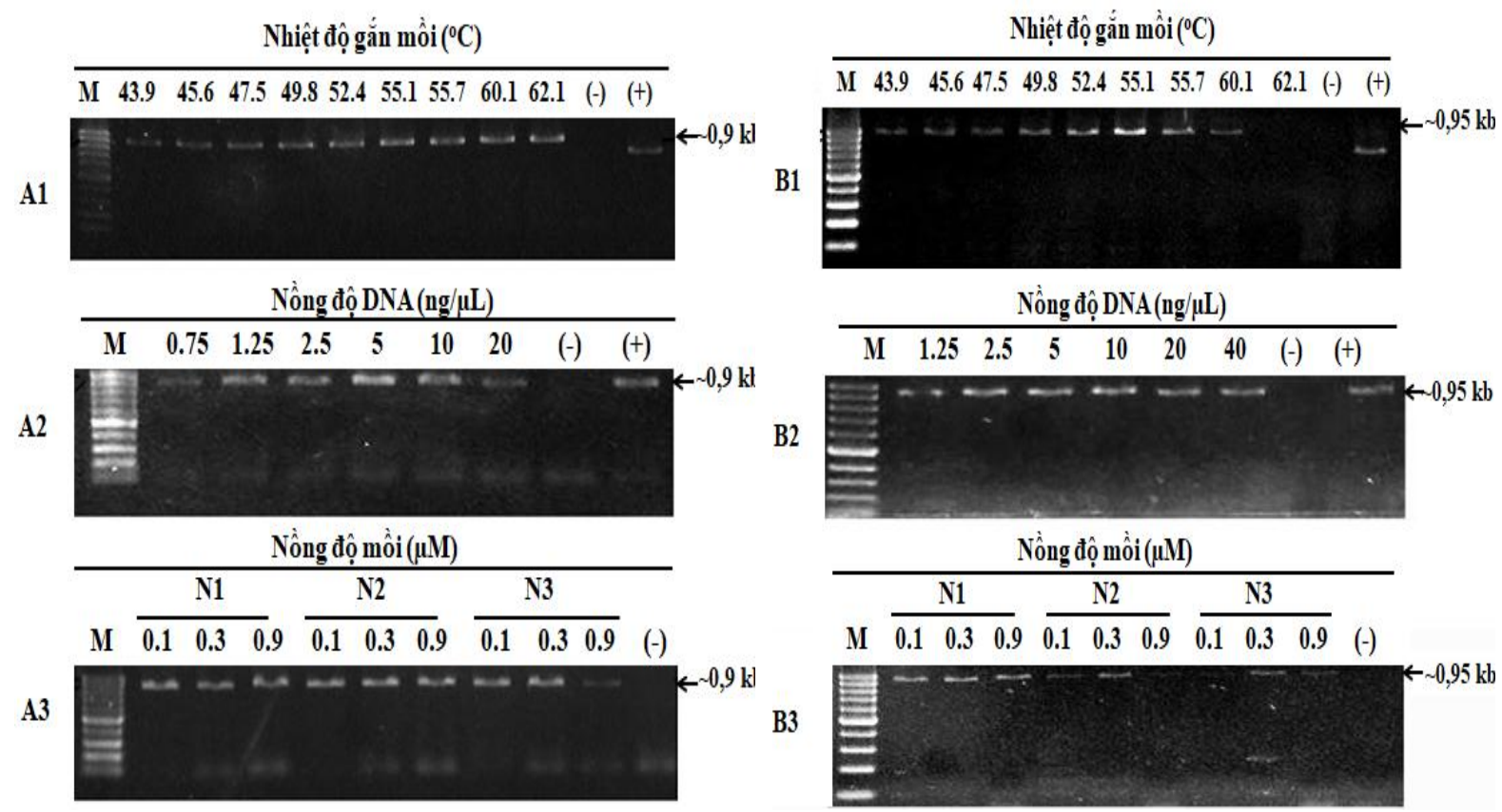

Hình 2. Ảnh điện di trên gel agarose 1,5\% sản phẩm PCR tối ưu nhân dòng gen ITS (cột $\mathrm{A}$ ) và matK (cột $\mathrm{B}$ ). Hình A1, B1 Tối ưu nhiệt độ gắn mồi. Hình A2, B2: Tối ưu nồng độ ADN. Hình A3, B3: Tối ưu nồng độ mồi. Làn M: Thang chuẩn ADN GeneRuler 100bp. Làn (+): Đối chứng dương. Làn (-): Đối chứng âm. 
A

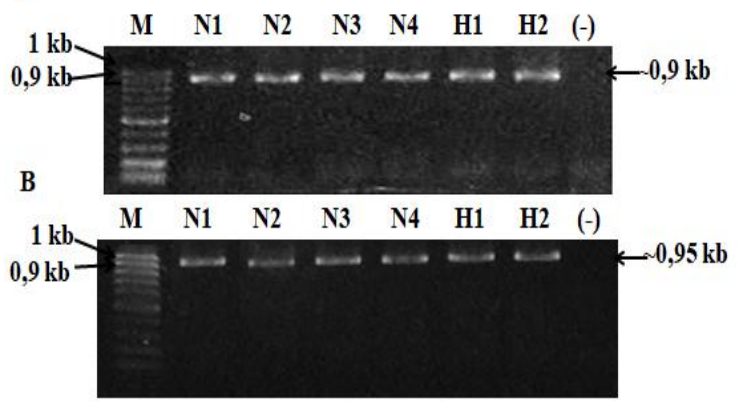

Hình 3. Ảnh điện di trên gel agarose $1,5 \%$ sản phẩm PCR nhân dòng gen ITS $(\mathrm{A})$ và $m a t K(\mathrm{~B})$ của 06 mẫu nghiên cứu.Làn $\mathrm{M}$ : Thang chuẩn $\mathrm{ADN}$ GeneRuler 100 bp. Làn (-): Đối chứng âm

Chúng tôi tiến hành phản ứng PCR với điều kiện như đã tối ưu, sử dụng $\mathrm{ADN}$ tổng số đã được tách chiết thành công. Sản phẩm khuếch đại được điện di trên gel agarose 1,5\%. Ghi nhận 06/06 mẫu nghiên cứu cho sản phẩm PCR đặc hiệu, sáng rõ với kích thước tương ứng khoảng 900 bp đối với gen ITS và khoảng 950 bp đối với gen matK (Hình 3).

Giải trình tự xác định kiểu gen các mẫu:dựa vào kết quả giải trình tự mẫu $\mathrm{PCR}$, hiển thị bằng phần mềm Sequencher 5.4.6 hoặc BioEdit ver 7.2.6.1. Độ dài đoạn gen của 06 mẫu nghiên cứu đối với gen ITS từ 851 (N4) đến 858 bp (N1); đối với gen $m a t K$ từ $882(\mathrm{H} 2)$ đến 910 bp $(\mathrm{N} 1)$.
Đánh giá độ tương đồng: kết quả so sánh mức độ tương đồng của các trình tự bằng chương trình BLAST và BioEdit ver 7.2.6.1 cho thấy vùng gen nhân lên thuộc đúng đoạn gen ITS và $m a t K$. Theo đó, vùng gen ITS nhân dòng với cặp mồi $17 \mathrm{SE} / 28 \mathrm{SE}$ bao gồm đầu $3^{\prime}$ tiểu phẩn nhỏ ribosome $18 \mathrm{~S}(100 \mathrm{bp})$, đoạn ITS hoàn chỉnh dài $610 \mathrm{bp}($ ITS1, 5,8S và ITS2), và đầu 5' tiểu phần lớn ribosome $28 \mathrm{~S}$ (135bp). Trong vùng gen ITS, đoạn ITS1 dài $122 \mathrm{bp}$, tiếp theo là đoạn $5,8 S$ dài 162 bp và đoạn ITS2 dài $227 \mathrm{bp}$. Ba mẫu $H$. nepalenis $\mathrm{N} 1, \mathrm{~N} 2$ và $\mathrm{N} 3$ giống nhau $100 \%$ và tương đồng hoàn toàn với $H$. nepalensis đối chứng (AJ131238.1); mẫu N4 sai khác với $H$. nepalensis đối chứng ở 1 vị trí nằm ở nucleotide 385. Trong nhóm mẫu $H$. helix, mẫu $\mathrm{H} 1$ giống $100 \%$ với $H$. helix đối chứng (AM503887.2), mẫu $\mathrm{H} 2$ sai khác với $H$. helix đối chứng ở hai vị trí 38 là và 129.

Đối với vùng gen $m a t K$, phản ứng nhân dòng sử dụng cặp mồi 390F/1326R thu được đoạn gen dài khoảng $920 \mathrm{bp}$. Vùng trình tự này nằm hoàn toàn trong gen matK có độ dài khoảng $1500 \mathrm{bp}$. Bốn mẫu $H$. nepalenis $\mathrm{N} 1, \mathrm{~N} 2, \mathrm{~N} 3$, và $\mathrm{N} 4$ có trình tự giống nhau và tương đồng $100 \%$ với $H$. nepalenis đối chứng (GQ434260.1). Hai mẫu H1, H2 tương đồng $100 \%$ với $H$. helix đối chứng (AJ319073.1). Thông tin chi tiết về các nucleotide sai khác giữa các mẫu nghiên cứu và các mẫu đối chứng được trình bày chi tiết trong Bảng 2 .

Bảng 2. Các nucleotide sai khác trên vùng trình tự ITS và matK giữa các mẫu nghiên cứu và các mẫu đối chứng. Hedera nepalensis đối chứng cho ITS: Trình tự AJ131238.1; Hedera nepalensis đối chứng cho matK: Trình tự GQ434260.1; Hedera helix đối chứng cho ITS: Trình tự AM503887.2; Hedera helix đối chứng cho matK: Trình tự AJ319073.1.

\begin{tabular}{|l|l|l|l|l|l|l|l|l|l|l|l|l|l|}
\hline Trình tự & \multicolumn{19}{l|}{ ITS } & 23 & 38 & 103 & 129 & 193 & 385 & 462 & 527 & 556 & 557 & 588 & 613 & 789 \\
\hline Vị trí & $\mathrm{T}$ & $\mathrm{A}$ & $\mathrm{C}$ & $\mathrm{C}$ & $\mathrm{C}$ & $\mathrm{C}$ & $\mathrm{C}$ & $\mathrm{A}$ & $\mathrm{G}$ & $\mathrm{A}$ & $\mathrm{C}$ & $\mathrm{T}$ & $\mathrm{G}$ \\
\hline $\begin{array}{l}\text { H.nepalensis } \\
\text { dối chúng }\end{array}$ &. &. &. &. &. &. &. &. &. &. &. &. &. \\
\hline $\mathrm{N} 1$ &. &. &. &. &. &. &. &. &. &. &. &. &. \\
\hline $\mathrm{N} 2$ &. &. &. &. &. &. &. &. &. &. &. &. &. \\
\hline $\mathrm{N} 3$ &. &. &. &. &. & $\mathrm{~T}$ &. &. &. &. &. &. &. \\
\hline $\mathrm{N} 4$ & $\mathrm{C}$ &. & $\mathrm{T}$ & $\mathrm{A}$ & $\mathrm{T}$ &. & $\mathrm{T}$ & $\mathrm{C}$ & $\mathrm{A}$ & $\mathrm{G}$ & $\mathrm{G}$ & $\mathrm{G}$ & $\mathrm{A}$ \\
\hline $\begin{array}{l}\text { H. helix } \\
\text { dối chúng }\end{array}$ & $\mathrm{C}$ &. & $\mathrm{T}$ & $\mathrm{A}$ & $\mathrm{T}$ &. & $\mathrm{T}$ & $\mathrm{C}$ & $\mathrm{A}$ & $\mathrm{G}$ & $\mathrm{G}$ & $\mathrm{G}$ & $\mathrm{A}$ \\
\hline $\mathrm{H} 1$ & $\mathrm{C}$ & $\mathrm{T}$ & $\mathrm{T}$ &. & $\mathrm{T}$ &. & $\mathrm{T}$ & $\mathrm{C}$ & $\mathrm{A}$ & $\mathrm{G}$ & $\mathrm{G}$ & $\mathrm{G}$ & A \\
\hline $\mathrm{H} 2$ & &
\end{tabular}




\section{Bàn luận}

Tế bào thực vật khó thu hồi ADN do nó có lớp thành cellulose dày và cứng. Nghiên cứu của Danka Boselová và cộng sự khuyến cáo sử dụng mẫu lá non, tươi để tách chiết ADN bởi khi đó hàm lượng $\mathrm{ADN}$ còn cao và thành cellulose vẫn còn mềm dẻo [17]. Trong phạm vi nghiên cứu này, do không đủ điều kiện sử dụng mẫu lá tươi, chúng tôi sử dụng mẫu lá khô được bảo quản trong silicagel. Vì vậy để lựa chọn được một quy trình tách chiết $\mathrm{ADN}$ tối ưu cho mẫu lá khô Dây thường xuân càng trở nên khó khăn hơn. Theo nghiên cứu của tác giả D.D. Long và cộng sự (2019) về phân tích đa hình di truyền với chỉ thị GBSSI, tách chiết mẫu Dây thường xuân được khuyến cáo sử dụng GeneJET Plant Genomic DNA Purification Mini Kit [18]. Chính vì vậy, chúng tôi đã tiến hành tách chiết $\mathrm{ADN}$ với kit thương mại này. Kết quả phân tích cho thấy, nồng độ $\mathrm{ADN}$ thu được từ $20 \mathrm{mg}$ mẫu lá khô là tương đối cao so với nghiên cứu của Danka Boselová và cộng sự [17]. Một số mẫu có giá trị OD 260/280 nằm ngoài khoảng $1,8-2,0$ có thể do tồn dư một số tạp chất như polysacaride, polyphenol, các hợp chất thứ cấp khác nhau trong tế bào thực vật sau khi tách chiết [19]. Tuy nhiên, các mẫu này vẫn nhân dòng các gen ITS và $m a t K 100 \%$, cho băng điện di sáng rõ và đặc hiệu, đủ điều kiện sử dụng cho các phân tích gen tiếp theo. Như vậy, GeneJET Plant Genomic DNA Purification Mini Kit của Thermo Scientific là kit tách chiết $\mathrm{ADN}$ hiệu quả từ mẫu lá khô Dây thường xuân phục vụ phân tích với chỉ thị ITS và $m a t K$.

Theo nghiên cứu của Sun và cộng sự với chỉ thị ITS, nhiệt độ gắn mồi tối ưu của cặp mồi 17SE/26SE dùng với $\mathrm{ADN}$ khuôn thu được từ mẫu Sorghum bicolor và Taq ADN polymerase là $58^{\circ} \mathrm{C}$ [15]. Với gen $\operatorname{mat} K$, Cuénoud và cộng sự (2002) đã chọn $48^{\circ} \mathrm{C}$ làm nhiệt độ gắn mồi cho cặp mồi 390F/1326R khi phân tích các mẫu thuộc bộ Caryophyllales [16]. Nhiệt độ gắn mồi khác nhau ở các nghiên cứu này so với nghiên cứu của chúng tôi là do sự khác nhau $\mathrm{ADN}$ polymerase được sử dụng, thậm chí có thể do ảnh hưởng bởi hệ thiết bị khác nhau. Chính vì vậy, tối ưu nhiệt độ gắn mồi là rất quan trọng và cần được thực hiện đầu tiên để có quy trình PCR ổn định. Thông qua kết quả tối ưu, chúng tôi đã đưa ra được chu trình nhiệt dùng chung cho cả hai gen ITS và $m a t K$, giúp phân tích cùng lúc hai gen này trong một lần chạy máy PCR. Đối với mẫu thực vật, nồng độ $\mathrm{ADN}$ khuôn cao thường ức chế phản ứng nhân dòng do sự tồn tại của các tạp chất còn tồn lưu cùng $\mathrm{ADN}$ khuôn. Điều này thể hiện rõ trong Hình 2A2, khi nồng độ $\mathrm{ADN}$ khuôn cao hơn $5 \mathrm{ng} / \mu \mathrm{L}$, lượng sản phảm $\mathrm{PCR}$ thu được giảm thể hiện qua băng điện di giảm dần về độ sáng. Chính vì vậy, tất cả các mẫu nghiên cứu đều được pha loãng về nồng độ $5 \mathrm{ng} / \mu \mathrm{L}$ để tiến hành phản ứng khuếch đại gen. Nồng độ mồi trong phản ứng $\mathrm{PCR}$ cũng là một thông số quan trong. Nồng độ mồi $0,3 \mu \mathrm{M}$ cho phản ứng $\mathrm{PCR}$ lên ổn định nhất.

Dựa trên kết quả so sánh các mẫu nghiên cứu trên phần mềm BLAST, chúng tôi đã nhân dòng thành công và chính xác 02 vùng trình tự quan tâm là $I T S$ và $m a t K$ ở Dây thường xuân với hiệu suất cao, có thể áp dụng mở rộng trên cỡ mẫu lớn hơn phục vụ cho các nghiên cứu phân tích đa dạng di truyền. Kết quả phân tích cho thấy bốn mẫu N1, N2, N3, N4 tương đồng 99,8\% - 100\% với trình tự $H$. nepalenis tham chiếu, hai mẫu $\mathrm{H} 1$ và $\mathrm{H} 2$ tương đồng $99,8 \%$ - 100\% với trình tự $H$. helix tham chiếu. Như vậy, kết quả phân tích gen bước đầu cho thấy có sự tương đồng với kết quả phân loại dựa trên hình thái. Như vậy chúng tôi khuyến cáo tiếp tục thu thập và phân tích các mẫu Dây thường xuân khác với chỉ thị ITS và $m a t K$ để có được bức tranh toàn cảnh hơn về đa dạng di truyền của loài này.

Đối với chỉ thị ITS, cặp mồi 17SE/28SE được sử dụng lần đầu tiên bởi Sun và cộng sự (1994) trong phân tích phát sinh gen cây cao lương (Sorghum bicolor), nhân lên đoạn gen ITS dài khoảng 588 bp [15]. Ngoài ra, cặp mồi này cũng đã được sử dụng ở nghiên cứu đánh giá đa dạng di truyền ở chi Lan hoàng thảo (Dendrobium) và đoạn gen ITS được nhân lên có độ dài 857 bp [20], kết quả này tương đồng với độ dài vùng gen ITS của Dây thường xuân được nhân lên trong nghiên cứu này. Đặc biệt, R. Vargas và cộng sự (1999) đã có nghiên cứu về 27 trình tự của 12 loài thuộc chi Hedera cũng sử 
dụng đoạn mồi 17SE/28SE. Phân thích kiểu nhân cho thấy loài $H$. nepalensis và $H$. helix có bộ nhiễm sắc thể lưỡng bội $2 n$ là 48 . Cũng tương đồng với nghiên cứu của chúng tôi, phân tích của R. Vargas cho thấy trong đoạn ITS hoàn chỉnh dài 610 bp thì vùng ITS1 dài 221-223 bp, 5,8S dài 163 bp và vùng ITS2 dài 224 bp. Có rất ít các đột biến điểm được tìm thấy ở vùng trình tự ITS nhưng chỉ thị này vẫn phân loại thành công được $H$. nepalensis với $H$. helix và 10 loài khác thuộc chi Hedera [21]. Nghiên cứu này chính là cơ sở để chúng tôi lựa chọn chỉ thị ITS phân tích đa dạng di truyền trên Dây thường xuân ở Việt Nam.

Đối với chỉ thị matK, cặp mồi 390F/1326R sử dụng trong nghiên cứu này đã được ứng dụng trong nhiều nghiên cứu trước đó và được khuyến cáo làm mã vạch trong phân loại thực vật. Trong nghiên cứu của Lei và cộng sự (2014) trên 27 loài thực vật có độc thuộc 22 chi và 17 họ ở Trung Quốc, cặp mồi này được đánh giá là hiệu quả cao trong định danh loài [22]. Ngoài ra, Sun và cộng sự (2001) cũng nhân lên được đoạn gen matK dài 907 bp giúp phân biệt Helleborus với các chi khác [23]. Năm 2002, Cuénoudsử dụng cặp mồi 390F/1326R khuếch đại khoảng 930 bp trình tự $m a t K$ giúp phân loại trong bộ Caryophyllales [16]. Độ dài đoạn gen matK được nhân lên bởi cặp mồi 390F/1326R của các nghiên cứu trên khá tương đồng với nghiên cứu của chúng tôi. Đối với chi Hedera, Grivet và cộng sự (2002) đã sử dụng 5 cặp mồi gối nhau để nhân dòng được đoạn gen trnK dài 2474 bp và chứa toàn bộ gen matK. Nghiên cứu này đã chỉ ra với 5 đột biến điểm thuộc vùng exon của $m a t K$ đã cho phép xác định được 6 halotype thuộc 4 loài là $H$. helix và $H$. hibernica, $H$. maderensis và $H$. Maroccana [13]. Như vậy, tuy vùng trình tự mat $K$ có tính bảo thủ cao nhưng vẫn là một chỉ thị tiềm năng trong việc phân loại và định danh các loài thuộc chi Hedera.

\section{Kết luận}

Chúng tôi đã xây dựng được quy trình phân tích gen ITS và matK trên Dây thường xuân. Kết quả này sẽ là tiền đề cho các nghiên cứu phân tích đa dạng di truyền và đánh giá chất lượng nguồn gen, phục vụ cho công tác bảo tồn và phát triển nguồn dược liệu Dây thường xuân tại Việt Nam.

Các tác giả chân thành cảm ơn nhóm nghiên cứu của PGS. TS. Phạm Thanh Huyền (Khoa Tài nguyên Dược liệu, Viện Dược liệu) đã giúp thu thập mẫu vật phục vụ cho nghiên cứu này.

\section{Lời cảm ơn}

Chúng tôi trân trọng cảm ơn Bộ Khoa học và Công nghệ Việt Nam đã tài trợ cho đề tài mã số NVQG-2018/02 để thực hiện nghiên cứu này.

\section{Tài liệu tham khảo}

[1] V.V. Chi. Dictionary of Vietnamese Medicinal Plants, Publ. House Medicine, Ho Chi Minh City, 2012 (in Vietnamese).

[2] D.H. Bich, D.Q. Cuong, B.X. Chuong, N. Thuong, D. T. Dam. The medicinal plants and animals in Vietnam, Hanoi Sci. Technol. Publ. House Hanoi, 2006 (in Vietnamese).

[3] A. Sadat, M. Alam, A. Rauf, W. Ullah, Biological screening of ethyl acetate extract of Hedera nepalensis stem, Afr J Pharm Pharmacol, 6 (2012) 2934-2937. https://doi.org/10.5897/AJPP12.828.

[4] T. Li, H. Pan, Y. Feng, H. Li, Y. Zhao, Bioactivityguided isolation of anticancer constituents from Hedera nepalensis K. Koch, S Afr J Bot, 100 (2015) 87-93. https://doi.org/10.1016/j.sajb.2015.05.011.

[5] L. Jafri, S. Saleem, N. Ullah, B. Mirza, In vitro assessment of antioxidant potential and determination of polyphenolic compounds of Hedera nepalensis K. Koch, Arab J Chem, 10 (2017) 3699-3706. https://doi.org/10.1016/j.arabjc.2014.05.002.

[6] S. Saleem, L. Jafri, I. ul Haq, L.C. Chang, D. Calderwood, B.D. Green, B. Mirza, Plants Fagonia cretica L. and Hedera nepalensis K. Koch contain natural compounds with potent dipeptidyl peptidase-4 (DPP-4) inhibitory activity, J Ethnopharmacol, 156 (2014) 26-32. https://doi.org/10.1016/j.jep.2014.08.017.

[7] W.J. Hashmi, H. Ismail, F. Mehmood, B. Mirza, Neuroprotective, antidiabetic and antioxidant effect of Hedera nepalensis and lupeol against 
$\mathrm{STZ}+\mathrm{AlCl} 3$ induced rats model, DARU, 26 (2018) 179-190. https://doi.org/10.1007/s40199018-0223-3.

[8] H. Ismail, A. Rasheed, I.-u. Haq, L. Jafri, N. Ullah, E. Dilshad, M. Sajid, B. Mirza, Five indigenous plants of Pakistan with Antinociceptive, antiinflammatory, antidepressant, and anticoagulant properties in Sprague Dawley rats, Evid Based Complement Alternat Med, 2017 (2017). https://doi.org/10.1155/2017/7849501

[9] N.D. Thanh. DNA marker techniques in study and selection of plant. Journal of Biology. 36 (2014) 265-294 (in Vietnamese). https://doi.org/10.15625/0866-7160/v36n3.5974.

[10] P.Z. Goldstein, R. DeSalle, Review and interpretation of trends in DNA barcoding, Front Ecol Evol, 7 (2019) 302. https://doi.org/10.3389/fevo.2019.00302.

[11] S. Abugalieva, L. Volkova, Y. Genievskaya, A. Ivaschenko, Y. Kotukhov, G. Sakauova, Y. Turuspekov, Taxonomic assessment of Allium species from Kazakhstan based on ITS and matK markers, BMC plant biol, 17 (2017) 258. https://doi.org/10.1186/s12870-017-1194-0.

[12] R.M. Bhagwat, B.B. Dholakia, N.Y. Kadoo, M. Balasundaran, V.S. Gupta, Two new potential barcodes to discriminate Dalbergia species, PloS one, 10 (2015) e0142965. https://doi.org/10.1371/journal.pone.0142965

[13] D. Grivet, R. Petit, Phylogeography of the common ivy (Hedera sp.) in Europe: genetic differentiation through space and time, Mol Ecol, 11 (2002) 1351-1362. https://doi.org/10.1046/j.1365294x.2002.01522.x.

[14] R. Li, J. Wen, Phylogeny and biogeography of Dendropanax (Araliaceae), an amphi-Pacific disjunct genus between tropical/subtropical Asia and the Neotropics, Syst Bot, 38 (2013) 536-551. https://doi.org/10.1600/036364413X666606.

[15] Y. Sun, D. Skinner, G. Liang, S. Hulbert, Phylogenetic analysis of Sorghum and related taxa using internal transcribed spacers of nuclear ribosomal DNA, Theor Appl Genet, 89 (1994) 2632. https://doi.org/10.1007/BF00226978
[16] P. Cuénoud, V. Savolainen, L.W. Chatrou, M. Powell, R.J. Grayer, M.W. Chase, Molecular phylogenetics of Caryophyllales based on nuclear $18 \mathrm{~S}$ rDNA and plastid rbcL, atpB, and matK DNA sequences, Am J Bot, 89 (2002) 132-144. https://doi.org/10.3732/ajb.89.1.132.

[17] D. Bošel’ová, J. Žiarovská, L. Hlavačková, K. Ražná, M. Bežo, Comparative analysis of different methods of Hedera helix DNA extraction and molecular evidence of the functionality in PCR Acta fytotechn zootechn, 19 (2016) 144-149. https://doi.org/10.15414/afz.2016.19.04.144-149.

[18] D.D. Long, Comparative analysis of different DNA extraction methods and preliminary analysis of genetic diversity of Hedera nepalensis K. Koch. in Vietnam based on GBSSI marker, VNU Journal of Science: Medical and Pharmaceutical Sciences, 35 (2019) 88-95 (in Vietnamese). https://doi.org/10.25073/2588-1132/vnumps.4165

[19] J.H. Cota-Sánchez, K. Remarchuk, K. Ubayasena, Ready-to-use DNA extracted with a CTAB method adapted for herbarium specimens and mucilaginous plant tissue, Plant Mol Biol Rep, 24 (2006)161. https://doi.org/10.1007/BF02914055.

[20] S. Xu, D. Li, J. Li, X. Xiang, W. Jin, W. Huang, X. Jin, L. Huang, Evaluation of the DNA barcodes in Dendrobium (Orchidaceae) from mainland Asia, PloS one, 10 (2015) e0115168. https://doi.org/10.1371/journal.pone.0115168.

[21] P. Vargas, H.A. McAllister, C. Morton, S.L. Jury, M.J. Wilkinson, Polyploid speciation in Hedera (Araliaceae): Phylogenetic and biogeographic insights based on chromosome counts and ITS sequences, Pl Syst Evol, 219 (1999) 165-179. https://doi.org/10.1007/BF00985577

[22] X. Lei, Y.W. Wang, S.Y. Guan, L.J. Xie, L. Xin, C.Y. Sun, Prospects and problems for identification of poisonous plants in China using DNA barcodes, Biomed Environ Sci, 27 (2014) 794-806. https://doi.org/10.3967/bes2014.115.

[23] H. Sun, W. McLewin, M.F. Fay, Molecular phylogeny of Helleborus (Ranunculaceae), with an emphasis on the East Asian-Mediterranean disjunction, Taxon, 50 (2001) 1001-1018. https://doi.org/10.2307/1224717. 